\title{
Making Disciplinary Research Audible
}

The Academic Library as Podcaster

Drew Smith, Meghan L. Cook, and Matt Torrence

\section{ABSTRACT}

Academic libraries have long consulted with faculty and graduate students on ways to measure the impact of their published research, which now include altmetrics. Podcasting is becoming a more viable method of publicizing academic research to a broad audience. Because individual academic departments may lack the ability to produce podcasts, the library can serve as the most appropriate academic unit to undertake podcast production on behalf of researchers. The article identifies what library staff and equipment are required, describes the process needed to produce and market the published episodes, and offers preliminary assessments of the podcast impact.

\section{INTRODUCTION}

The academic library has always had an essential role in the research activities of university faculty and graduate students, but until the last several years, that role has primarily focused on assisting university researchers with obtaining access to all relevant published research in their fields, making it possible for those researchers to complete a thorough literature review. More recently, that role has evolved to encompass assisting with other aspects of research and publication, including consulting on copyright-related issues, advising researchers on the most appropriate places to publish, preserving publications and data in institutional repositories, helping tenure-track faculty to evaluate their research impact as part of the tenure and promotion process, and hosting open-access journals.

Meanwhile, libraries of all types have experimented in the last ten to fifteen years with using social media to promote library collections, services, and events. Many libraries have taken advantage of Facebook, Twitter, and YouTube as part of these efforts. Increasingly, libraries have incorporated makerspaces so that library patrons can create and edit video and audio files, meaning that this same equipment and software is now available to librarians and other library staff for their own purposes. This has resulted in libraries producing promotional videos and podcasts.

The dramatic increase in mobile technology (smartphones and tablets) ownership and usage over the last decade has resulted in an increase in the consumption of podcasts wherever the listener happens to be when their ears are not otherwise fully occupied, such as commuting, exercising, and engaging in home chores. As a result, academic libraries are now finding themselves in an excellent position to use podcasting for instructional and promotional purposes in an effort to reach a broad audience.

What happens when the university library combines its inherent interest in supporting the promotion of faculty and graduate student research with its ability to create podcasts to quickly and inexpensively reach an international audience? This paper documents the efforts of an academic library at a high-level research university to partner with one of the university's

Drew Smith (dsmith@usf.edu) is Associate Librarian, University of South Florida. Meghan L. Cook (mlcook3@usf.edu) is Coordinator of Library Operations, University of South Florida. Matt Torrence (torrence@usf.edu) is Associate Librarian, University of South Florida. (C) 2020. 
academic departments to use podcasting to promote the research done by that department's faculty and doctoral candidates. We will describe which library staff were involved, how the podcast was planned, the execution of the podcasting process, the issues that were encountered throughout the process, and how the impact of the podcast was assessed. Calling: Earth, the podcast produced by the University of South Florida (USF) Libraries, can be found at http://callingearth.lib.usf.edu/.

\section{LITERATURE REVIEW}

Podcasting as a means for promoting scholarly communication is a relatively new and uncommon idea in a library setting, therefore the extant literature is scarce on the subject. A high percentage of the contemporary articles on the aforementioned topic focus on the use of podcasts as a means to satisfy a wide array of student learning needs. While pedagogical best practices knowledge is useful, what current literature does exist is not an exact match for the concept of promoting scholarly communication, which offers subject specificity, faculty and graduate interaction, marketing of libraries, and research visibility as aggregate goals. What follows in this literature review is a summary of a slice of the literature related to podcasting, academia, and/or libraries.

The researchers chose as a starting point to look at the general use of podcasting, as well as social media, in various academic and library environments. In a recent article on the use of social media and altmetrics, for example, the increased use of these tools is outlined, but with numerous caveats regarding the initial non-probabilistic methods of gathering information on the how and why of their adoption. ${ }^{1}$ To further emphasize the use of podcasts and, in a related way, social marketing, an examination of an article related to Association of Research Libraries (ARL) efforts in this vein was examined. A comprehensive study of ARL member libraries published in 2011, with not much on this topic published since this date, demonstrated in figure 1 of their research that five of the 37 respondents contained recorded interviews and only one included scholarly publishing content. ${ }^{2}$ This ten-year vacuum in further research was unexpected but indicates an opportunity for a new type of podcast focusing on academic production.

Scholars in academic libraries have long examined student preferences for new technologies and types of information transfer, including the use of podcasts. A study from Sam Houston State University found that 36 percent of users in 2011 were using podcasts for recreational purposes as opposed to much lower use for academic and scholarly communication benefits. ${ }^{3}$ In the future, academic creation and utilization of podcasts for scholarly communication is ripe for a hearty statistical and qualitative analysis. Specific to this inquiry, the application of podcasts for scholarly communication in a subject discipline present in the literature appears to be lacking. Furthermore, this literature review emphasizes the dearth of research that relates to promoting the research efforts of geosciences faculty and graduate students.

In terms of recent literature, there are also a number of publications available that deal with the history and evolution of podcasting in education and, specifically, higher education. One such current work provides an excellent outline of this growth in use, as well as outlining several major types, or genres, of podcasting in these types of environments. Following a strong and succinct overview of the technology and its use in college and university settings, the author continues to effectively define, with examples, the three main genres they have identified: the "Quick Burst," the "Narrative," and the "Chat Show." 4 The model that most represents USF's Calling: Earth program is "Narrative," as this includes a subcategory of "Storytelling." This work is truly beneficial for any group or individual developing, or improving, an educational podcast effort. 
In 2011, Peoples and Tilley outlined the emergence of podcasts to disseminate information in academic libraries. One of the excellent questions that arises from this work deals with the access, advancement, and archiving of the content; is this content to be archived, or cataloged, as more permanent material, or is it electronic ephemera ${ }^{5}$ This is a question for the USF Calling: Earth podcast group going forward as the level and quality of content and, ideally, use is expanded.

Additionally, educators are studying more about the limitations of podcasts; not to rule them out as academic tools, but to inspire and enhance the best possible outcomes. One excellent warning to be heeded by any library hoping to utilize podcasts for education and dissemination of research is summed up well in this quote: "If students do not utilize or do not realize the benefits of the selfpacing multimedia characteristics of podcasting, then the resource becomes a more likely contributor to cognitive overload." 6

There have been a small number of the quantitative elements of podcast use in academic libraries. An article in VINE: The Journal of Information \& Knowledge Management Systems outlined, via content analysis and other methods, various unique and shared characteristics of existing academic podcasts, while also furthering the concept of podcasting as a "library service."7 This may not have been the first publication to make this assertion, but this is a view that is also held by these authors and this view shapes the development and advancement of the USF Libraries podcasting efforts. Librarians of all types must be wary, however, as there are numerous articles that focus on the better understanding of student learning preferences. As presented by a recent article on the success of satellite and distance learners showed, though, these tools often hit the spot on the delivery preferences for these types of students. ${ }^{8}$

Switching gears to a bit more topic specificity, a number of news and academic articles were identified on the use of podcasts in areas of the geosciences. One such effort is the Geology Flannelcast. The development and implementation of this combination of education and entertainment, which is also a goal of these authors, is outlined by the creators' poster presentation at a recent Geological Society of America conference. With a focus on the increasing ease of podcasting technology, reduced cost of equipment, and the use of "conversational atmosphere" within a pedagogical framework, this model stood out as one worth studying. ${ }^{9}$ Furthermore, the geosciences are, or can be, interesting and exciting. A recent podcast on communicating geosciences with fun and flair is just the encouragement this research group needed to go all-in on this project. And that the geosciences are far from boring! ${ }^{10}$

As is evidenced by an examination of current and historical literature on this topic, there are multiple opportunities for further exploration and library efforts, expressly as one of the main points of this work is to emphasize faculty and graduate research efforts and scholarly communication and original content creation. In addition to the focus on these publications and presentation efforts, the results will be measured by the initial assessment projects including download and utilization data and, hopefully, positive feedback from participants and library administration. Further measurement is expected to demonstrate advanced citation counts and downloads of the publications of the faculty and graduate student interviewees. It will be correlation and not causation, of course, but the team hopes to have positive feedback for participants and the library. 


\section{STAFFING}

As with any successful project, a project to produce a podcast focused on academic research had to begin with individuals who had either the interest or the expertise, ideally both, to initiate the work. One was an associate librarian with more than 13 years of experiencing in producing regular podcasts, while the other was a library staff member who was a doctoral candidate serving on the USF Libraries Research Platform Team (RPT) for the USF School of Geosciences.

The RPT was already tasked with assisting the Geosciences faculty and graduate students in maximizing the impact of their work and had been using various means in order to accomplish this, such as an institutional repository for research output, and tools to measure the impact of previously published work. During a conversation in late 2018, the librarian suggested to the RPT staff person that podcasting could be used to promote research to a variety of audiences, including USF faculty and students, faculty and students at other universities, K-12 science teachers, and members of the general public (both local and beyond).

The librarian offered to initiate the podcast and train the RPT staff on how to continue the podcast after a number of episodes had been produced. The librarian brought to the project the needed expertise with launching and maintaining a podcast, while the RPT doctoral candidate was already familiar with the Geosciences faculty and other doctoral candidates and could identify those who would make good candidates for being interviewed about their research.

\section{PLANNING}

The initial planning for the podcast began approximately two months before the first episode release. The original project managers and podcast creators met a number of times to discuss logistics, equipment, and staffing needs, and to agree upon a podcast name (Calling: Earth). Since the notion of podcasting for researcher promotion was an unexplored territory, the support from higher administration was cautious. However, after production of the first episodes, traction behind the podcast grew and additional support for future endeavors was received.

The podcasters acquired handheld recording equipment, a Tascam DR-05 Linear PCM Recorder, from the USF Libraries Digital Media Commons and tested it out in multiple environments (for instance, a quiet office versus a recording studio) to find the optimal location to record the interviews. We found the hand-held recording equipment worked well in a quiet office and allowed for travel to the researcher's office if they requested.

The podcast creation team discussed how to add intro and outro music to the podcast that would not violate any copyright restrictions but that would fit the mood of the podcast. The RPT staff person knew of a local Tampa-based band, The Growlers, as a potential source for music because the bass guitarist was an adjunct professor and alumnus of the USF School of Geosciences. The alumnus gave permission to use a portion of the band's recorded music for the podcast.

A hosting service was needed to host and publish the podcast. The librarian suggested using Libsyn, because of their 13 years of previous experience with the platform, Libsyn's inexpensive hosting plan, and the ability to acquire statistics including the geographic locations (countries and states) where the podcast was being downloaded. 


\section{EXECUTION}

Potential interviewees were contacted via email and invited to be interviewed. Once the potential interviewee agreed, a time and a place to conduct the interview was agreed upon. The RPT staff person determined what the most recent research was for each interviewee, and then provided that content to the librarian host for review. The host then prepared interview questions based on the research content. The host went over the questions with the interviewee before the interview began to clear the content with the interviewee and to make sure everything would be covered in the interview that the interviewee wished to cover. The interviews took approximately 30 minutes to an hour. Editing of the podcast was done using GarageBand, allowing for the addition of the music to the beginning and end, as well as the host introducing both the general podcast and the specific episode, identifying the academic units involved in the podcast, indicating how listeners might provide feedback, and thanking the music group for allowing the use of their music. In a few rare cases, small interview segments were removed, usually due to the interviewee feeling that it did not represent them well.

\section{CHALLENGES}

As with any new endeavor, challenges were faced at all stages in the process of getting the podcast to production and beyond.

\section{Buy-in from Library Administration}

An early challenge was to gain buy-in from the library administration. This began with requesting that the library fund the hosting service, and the feeling of the administrator was that it was a worthwhile experiment, at least in the short term. Once a number of episodes had been produced, the library administration had a better sense of the quality of the production and how it would serve the interests of the library in its academic support role.

\section{Lack of Budget}

With no budget for this project (beyond the administration's monthly payment of the hosting service), the podcasters were at the mercy of the quality of the recorders available for library checkout. If the recorders did not produce a high-quality recording, the podcast would possibly lack the sophistication needed for production. Also, high-quality graphics work was needed and required us to look into other library units for help with creating a logo.

\section{Getting the Podcast into Apple Podcasts}

Once content was being produced and published, it was time to submit the podcast to Apple Podcasts. Apple initially rejected the submission because the first logo looked very similar to an iPhone. It should be noted that Apple did not supply a specific explanation of what copyright was being infringed, so the podcasters were faced with making a best guess as to what the problem was. Based on our assumption, we changed the logo and resubmitted the podcast. A further problem arose when Apple required that the new submission use a different RSS feed than the original submission. Eventually the podcasters sought assistance from Libsyn, who explained how to make a minor change to the URL of the RSS feed so that the podcast could be successfully resubmitted. 


\section{New Logo Creation}

The first logo continued to be used for the entire first season, but before the second season was released, the library's new communications and marketing coordinator assisted with the creation of a new logo that looked more sophisticated and more in-line with other podcast logos. Having an in-house graphics designer was extremely helpful in rolling out a new logo (See figures 1 and 2).

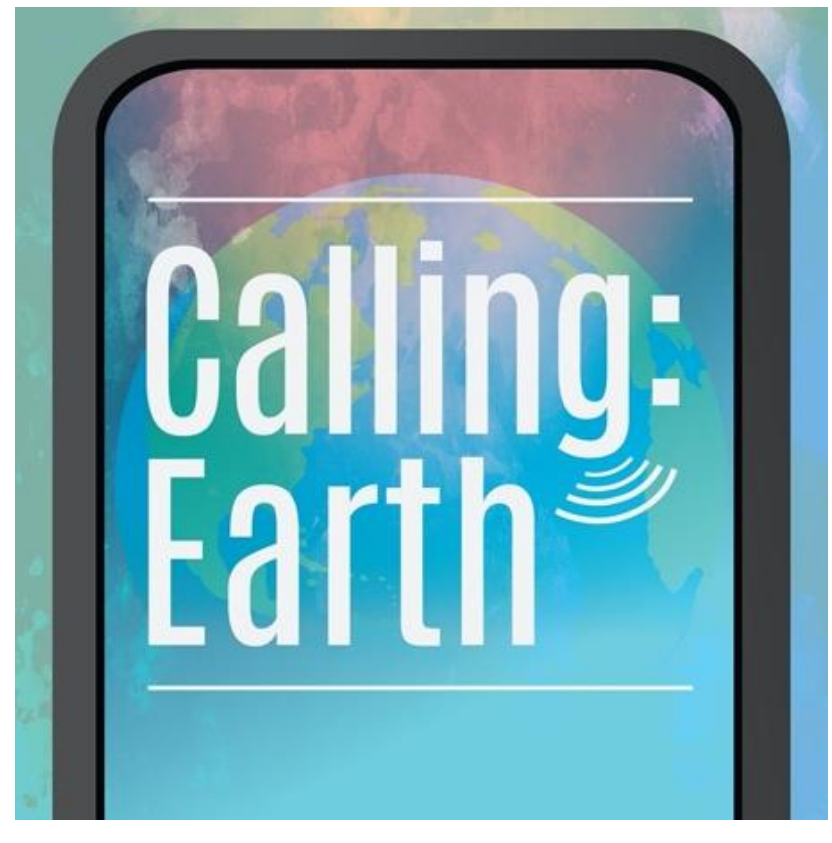

Figure 1. Season 1 Logo

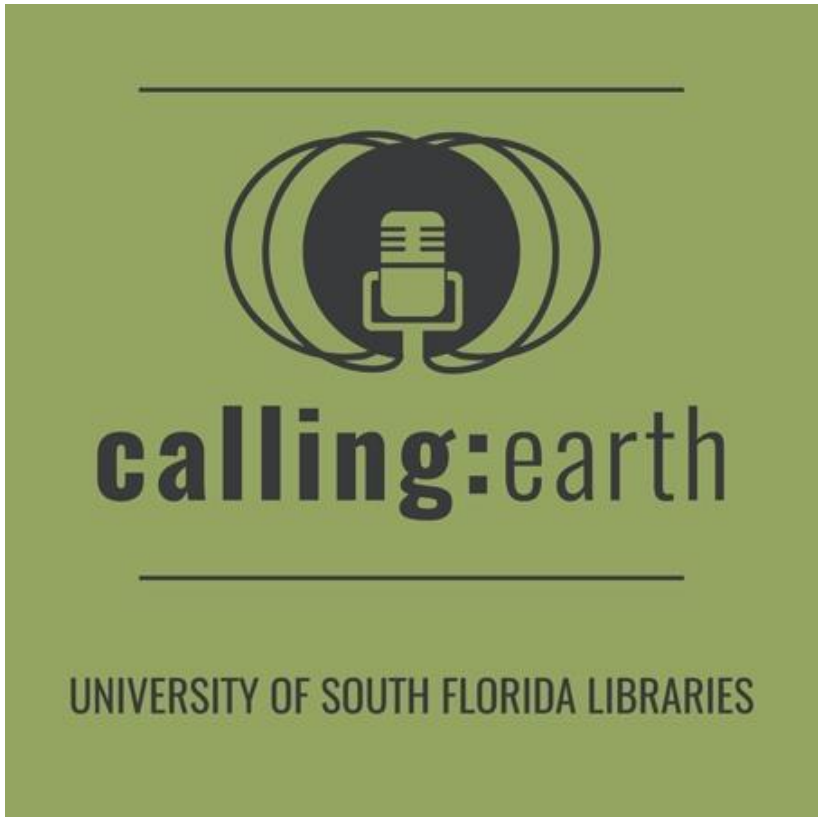

Figure 2. Current Logo

\section{Setting Up Interviews}

Identifying potential interviewees, requesting interviews, and setting good times and locations for the interviews brought on another batch of challenges. The USF School of Geosciences is composed of geologists, geographers, and environmental scientists so when planning out the schedule for the potential interviewees, an effort was made to involve a wide range of researchers. Some potential interviewees denied the request altogether, while others were not available for the needed time period. Given that the podcast was released every two weeks, there was a little wiggle room for scheduling hiccups, but once or twice a last-minute request to a new potential interviewee was made to ensure production stayed on schedule. Where the interview was held and what time required a lot of back-and-forth emails between the RPT staff person and the interviewee. Preference on time and location was given to the interviewee, but it was requested that, if they did not want to come to the library to be interviewed, their own office/lab space could be used if it was a sufficiently quiet environment for recording purposes.

\section{Comfortability of the Interviewee}

Once an interview began, the challenge of engagement from the host and comfortability of the interviewee became apparent. The host had to engage the researcher at a level appropriate for a general audience, which was challenging given that the research done by the USF School of Geosciences is often at a high-level of critical thinking and problem-solving. To add on to the complexity of the research being explained, the comfort level of the interviewee had the potential 
to dampen the interview. One researcher was so uncomfortable speaking in an interview that they typed up in advance what they wanted to say.

\section{ASSESSMENT}

\section{Libsyn Statistics}

According to Libsyn statistics (as of July 17, 2020) there were a total of 3,593 unique downloads from 48 different countries of the published 35 episodes of Calling: Earth. In table 1, the 48 countries where Calling: Earth has been downloaded are shown, as well as how many times the podcast has been downloaded in each country. It is worth noting that there are 105 downloads that do not have a location specified, so the total of the downloads in table 1 does not equal the total number of downloads reported by Libsyn.

Table 1. Downloads by Country

\begin{tabular}{|l|l|l|l|}
\hline Name & Downloads & Name & Downloads \\
\hline United States & 2,729 & Chile & 3 \\
\hline United Kingdom & 103 & Denmark & 3 \\
\hline India & 98 & Romania & 3 \\
\hline Australia & 88 & South Africa & 3 \\
\hline France & 62 & Yemen & 3 \\
\hline Ireland & 50 & Argentina & 2 \\
\hline Bangladesh & 43 & Ecuador & 2 \\
\hline Spain & 37 & Poland & 2 \\
\hline $\begin{array}{l}\text { Russian } \\
\text { Federation }\end{array}$ & 36 & Taiwan & 2 \\
\hline Norway & 30 & Turkey & 2 \\
\hline Portugal & 30 & Belgium & 1 \\
\hline Germany & 20 & Bulgari & 1 \\
\hline Japan & 19 & Colombia & 1 \\
\hline Mexico & 18 & Costa Rica & 1 \\
\hline Italy & 14 & Estonia & 1 \\
\hline Netherlands & 12 & Greece & 1 \\
\hline New Zealand & 11 & Latvia & 1 \\
\hline Brazil & 9 & Macedonia & 1 \\
\hline Korea, Republic of & 9 & Nigeria & 1 \\
\hline Czech Republic & 7 & Pakistan & 1 \\
\hline Ukraine & 7 & Saudi Arabia & 1 \\
\hline China & 6 & $\begin{array}{l}\text { United Arab } \\
\text { Emirates }\end{array}$ & 1 \\
\hline Hong Kong & 5 & Vietnam & 1 \\
\hline Sweden & 4 & Without a & \\
location & 105 \\
\hline Canada & 3 & & \\
\hline
\end{tabular}




\section{Preliminary Survey and Scholarly Impact}

A survey was sent out to the interviewees to gauge their impressions of the podcast and to see if they had noticed any impact to their citations or document downloads. Our goal for the survey was to find out if the podcast was accomplishing the intention for starting a podcast, which was to increase researcher impact by research dissemination, as well as to inform the podcast processes and procedures. The questions asked were:

1. In what ways do you view the Calling: Earth podcast as a way to positively affect your research impact?

2. What evidence do you have, if any, to suggest your research has been positively impacted because of being an interviewee on the Calling: Earth podcast?

3. What would you have liked to be different about your interview process for the Calling: Earth podcast?

4. What suggestions do you have for the future seasons of the Calling: Earth podcast? For example, should the format change, the focus be different, change the length of the interview, etc.

Furthermore, each interviewee was asked to contribute their scholarship to the library's institutional repository, Scholar Commons, to allow for the archiving of their research publications and to use as a means of tracking scholarship impact as a result of the podcast. Once an interviewee's scholarship was placed in Scholar Commons, a Selected Works profile was created so that a direct link to the scholar's work could be disseminated through the podcast notes. Impact on faculty has also been noteworthy. The download totals for faculty interview participants (when comparing roughly the same amount of time just prior to and following their publish ed interview) showed an average increase of 30 percent and suggest a strong correlative link between the podcast and researcher impact. Furthermore, anecdotal evidence from interviewees such as "puts my name out there to a wider audience," "enhances the visibility of my work," and "allow others to hear about [my research] in a more passive way" indicates the potential impact a researcher can see from being a part of the podcast.

A second survey was sent to the faculty, students, and staff of the entire School of Geosciences to determine who was listening to the podcast and conversely, who was not, and their reasons for listening or not listening. The survey contained five questions in total, but according to how the participant selected their answers, not all were available to be answered (figure 3). The first question asked their status in the School of Geosciences (faculty, staff, undergraduate, graduate, or other). The second question asked if they had heard of the podcast and if they had or had not listened to it. If a participant chose the option that they had never heard of the podcast, then the survey ended for them. If a participant chose the option that they had heard of the podcast, but had not listened to it, then the survey directed them to a question that asked them to provide reasons they had not listened to the podcast. If a participant chose the option that they had heard of the podcast, and had listened to at least one episode, the survey directed them to a question that asked how many episodes the participant had listened to and for what reasons were they listening to the podcast. This data was collected to inform the future direction of the podcast. 


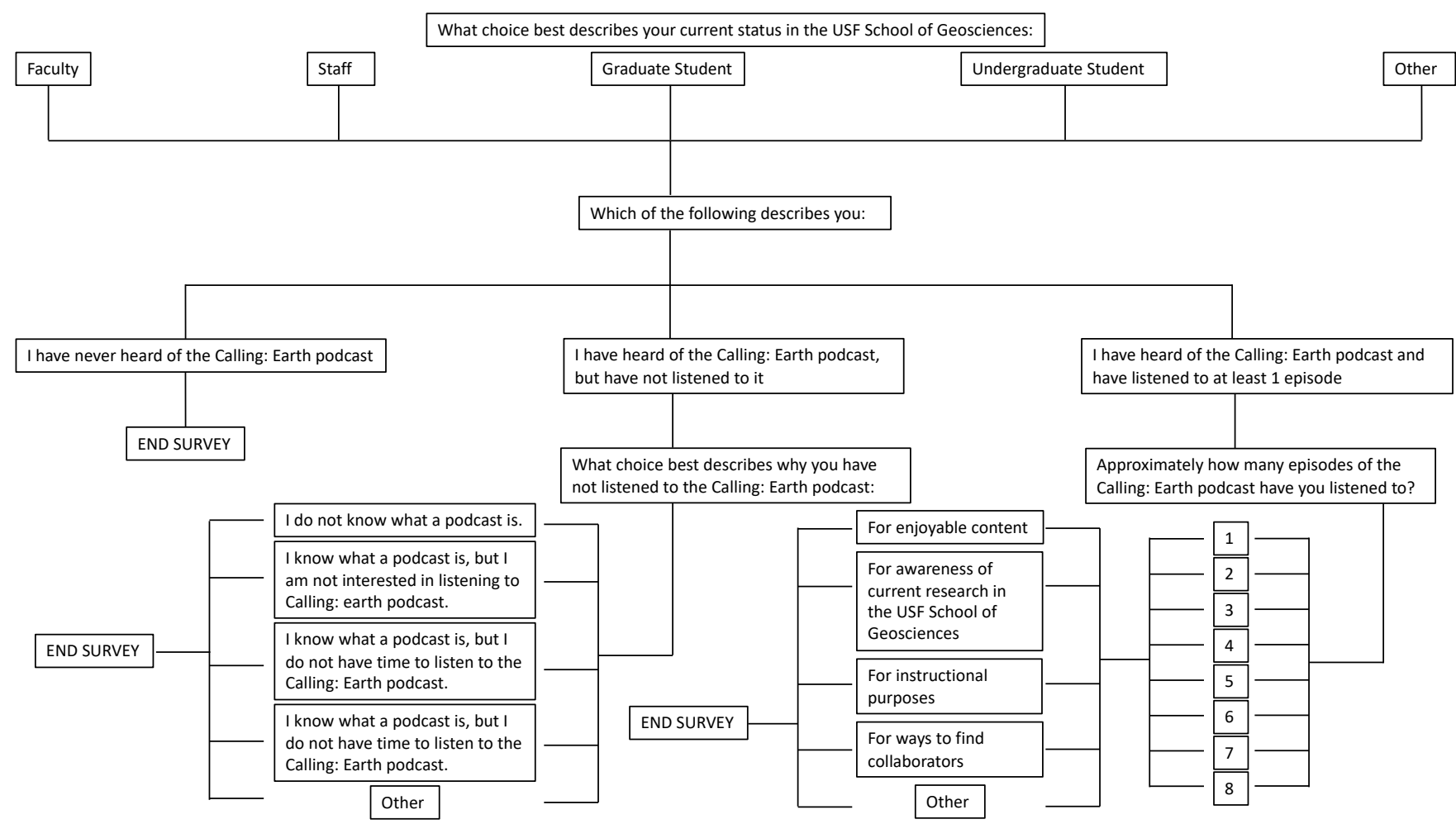

Figure 3. Flow Chart for the Entire School of Geosciences Survey

\section{CHECKLIST FOR PODCAST PLANNING/EXECUTION}

Based on our experiences in the production of the Calling: Earth podcast, we recommend that academic librarians and library staff use the following list to help with planning and executing the production of their own podcasts:

- Get general buy-in from library staff and administration, and update as the planning progresses and budgeting is needed.

- Decide on goals, audience, content, format, frequency of production, and methods of assessment.

- Work with media staff to design marketing, including podcast title (avoiding duplication with other podcasts) and logo development.

- Choose a podcast hosting service.

- Identify relevant staff for hosting, recording, editing, and publishing and train as needed.

- Evaluate existing hardware and software and make additional purchases as needed.

- Contact potential interviewees and create a schedule.

- Prepare customized interview questions and share as appropriate with interviewees.

- Record interviews.

- Edit and publish episodes.

- Submit podcast to Apple Podcasts, Spotify, and other popular podcast directories.

- Monitor statistics.

- Continue to engage in marketing and assessment activities. 


\section{CONCLUSIONS AND FUTURE DIRECTIONS}

Enthusiasm and anecdotal positive feedback are enough fuel for current activities and levels of enthusiasm and the future of podcasting in libraries also appears open and exciting. At the USF Libraries, Calling: Earth is currently in its third season and with each new episode, new ideas and increased archival content become a permanent part of the library's legacy and collections. This is another area ripe for future exploration, as this type of original content is archived, cataloged, and disseminated, becoming another part of regular academic impact measure.

In this vein, the USF Libraries podcasting group plans to further codify cyclical assessment tools, including the receipt of IRB clearance for future surveys and data collection. In addition to cleaning up and refining these assessment practices, this will also provide the opportunity to publish and present publicly on more specific data. Ideally, the group will be able to correlate the show's presence to positive citation or metrics levels with show participants. The USF Libraries Geosciences RPT is currently collecting baseline aggregate information, which could then be compared following further maturation and dissemination of the podcast. Causality may never be within reach, but any positive impacts will be exciting and beneficial.

It is also the hope of those involved with Calling: Earth that it might provide a model or template for other RPT or library podcasts or media efforts. One of the current benefits is the strong and effective support from the Development and Communication directors at the USF Libraries and their partnerships in the future will certainly be key to the success of this and any other potential projects of this type. In closing, the academic library podcasting landscape is wide-open for further exploration and examination, and the USF Libraries plans to lead and learn.

\section{ENDNOTES}

${ }^{1}$ Cassidy R Sugimoto et al., "Scholarly Use of Social Media and Altmetrics: A Review of the Literature," Journal of the Association for Information Science and Technology 68, no. 9 (2017): 2,037-62.

2 James Bierman and Maura L. Valentino, "Podcasting Initiatives in American Research Libraries," Library Hi Tech 29, no. 2 (May 2011): 349, https://doi.org/10.1108/07378831111138215.

${ }^{3}$ Erin Dorris Cassidy et al., "Higher Education and Emerging Technologies: Student Usage, Preferences, and Lessons for Library Services," Reference \& User Services Quarterly 50, no. 4 (2011): 380-91, https://doi.org/10.5860/rusq.50n4.380.

${ }^{4}$ Christopher Drew, "Educational Podcasts: A Genre Analysis," E-Learning and Digital Media 14, no. 4 (2017): 201-11, https://doi.org/10.1177/2042753017736177.

${ }^{5}$ Brock Peoples and Carol Tilley, "Podcasts as an Emerging Information Resource," College \& Undergraduate Libraries 18, no. 1 (January 2011): 44, https://doi.org/10.1080/10691316.2010.550529.

${ }^{6}$ Stephen M Walls et al., "Podcasting in Education: Are Students as Ready and Eager as We Think They Are?”, Computers \& Education 54, no. 2 (January 2010): 372, https://doi.org/10.1016/j.compedu.2009.08.018. 
7 Tanmay De Sarkar, "Introducing Podcast in Library Service: An Analytical Study," Vine 42, no. 2 (2012): 191-213, https://doi.org/10.1108/03055721211227237.

${ }^{8}$ Lizah Ismail, "Removing the Road Block to Students' Success: In-Person or Online? Library Instructional Delivery Preferences of Satellite Students," Journal of Library \& Information Services in Distance Learning 10, no. 3-4 (2016): 286-311, https://doi.org/10.1080/1533290X.2016.1219206.

${ }^{9}$ Jesse Thornburg, "Podcasting to Educate a Diverse Audience: Introducing the Geology Flannelcast," in Innovative and Multidisciplinary Approaches to Geoscience Education (Posters) (Boulder, CO: Geological Society of America, 2015).

${ }^{10}$ Catherine Pennington, "PODCAST: Geology Is Boring, Right? What?! NO! Why Scientists Should Communicate Geoscience...," n.d., https://britgeopeople.blogspot.com/2018/10/PODCASTgeology-is-boring-right.html. 